Scientific/Clinical Article

\title{
Effectiveness of virtual reality in the treatment of hand function in children with cerebral palsy: A systematic review
}

\author{
Chandrasekar Rathinam MPT, MSc ${ }^{\mathrm{a}, *}$, Vikram Mohan MPT ${ }^{\mathrm{b}}$, Janet Peirson MCSP ${ }^{\mathrm{c}}$, Jane Skinner PhD ${ }^{\mathrm{d}}$, \\ Kalidass Subash Nethaji MPH ${ }^{c}$, Isla Kuhn MA, MSc ${ }^{e}$

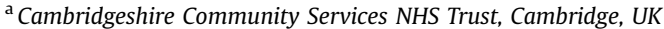 \\ ${ }^{\mathrm{b}}$ Faculty of Health Sciences, Universiti Teknologi MARA, Puncak Alam, Selangor, Malaysia \\ ${ }^{\mathrm{c}}$ Private Practitioner (Physiotherapy), Cambridge, UK \\ ${ }^{\mathrm{d}}$ Faculty of Medicine and Health Sciences, Norwich Medical School, University of East Anglia, Norwich, UK \\ ${ }^{\mathrm{e}}$ University of Cambridge Medical Library, University of Cambridge School of Clinical Medicine, Cambridge, UK
}

\section{A R T I C L E I N F O}

\section{Article history:}

Received 8 May 2017

Received in revised form

8 December 2017

Accepted 14 January 2018

Available online $\mathrm{xxx}$

\section{Keywords:}

Virtual reality

Cerebral palsy

Hand function

Systematic review

ICF

Computer games

\begin{abstract}
A B S T R A C T
Study Design: Systematic review.

Introduction: Children with cerebral palsy $(\mathrm{CP})$ may have limited use of their hands for functional activities and for fine motor skills. Virtual reality (VR) is a relatively new and innovative approach to facilitate hand function in children with $\mathrm{CP}$.

Purpose of the Study: The primary purpose of this study was to determine the effectiveness of VR as an intervention to improve hand function in children with CP compared to either conventional physiotherapy or other therapeutic interventions. The secondary purpose was to classify the outcomes evaluated according to the International Classification of Functioning, Disability and Health (ICF) dimensions.

Methods: A International prospective register of systematic reviews (PROSPERO)-registered literature search was carried out in August 2015 in MEDLINE, CINAHL, ERIC, HealthSTAR, AMED, BNI, Embase, PsycINFO, PEDro, Cochrane Central Register, DARE, OTSeeker, REHABDATA, HaPI, CIRRIE, and Scopus. PRISMA guidelines were followed. Only randomized controlled trials (RCTs) were included, and their methodological qualities were examined using the Cochrane collaboration's risk of bias (RoB) tool. A narrative synthesis was performed.

Results: The 6 RCTs published on this topic provide conflicting results. Four studies reported improved hand function ( 2 low RoB, 1 high RoB, and 1 unclear RoB), whereas 2 studies reported no improvement. All of the RCTs reported the activity element of ICF, but no study explicitly described the effect of VR intervention based on the ICF model.

Conclusion: The role of VR ti imrpove hand fucntion in children with $\mathrm{CP}$ is unclear due to limited evidence; use as an adjunct has some support.
\end{abstract}

(c) 2018 Hanley \& Belfus, an imprint of Elsevier Inc. All rights reserved.

\section{Introduction}

Cerebral palsy (CP) is a nonprogressive neurodevelopmental disorder which begins in the early stage of life. ${ }^{1}$ The motor disorders are often accompanied by a disturbance of sensation, perception, cognition, communication, behavior, epilepsy, and by secondary musculoskeletal problems. ${ }^{1,2}$ Children with $\mathrm{CP}$ have

\footnotetext{
Conflict of interest: The authors have no conflicts of interest to disclose.

* Corresponding author. Paediatric Physiotherapist, Cambridgeshire Community Services, Block 13, Ida Darwin, Fulbourn, Cambridge, CB21 5EE, UK. Tel.: +44 (0) 1223883382.

E-mail address: chandrasekar.rathinam@nhs.net (C. Rathinam).
}

postural difficulties, changes in muscle tone, and may have limited movement in the upper and/or lower limbs. ${ }^{3}$ Affected children with increased tone usually develop muscle tightness and subsequently joint deformities. These issues contribute to the limited use of the extremities for functional activities. When the hands are affected, there is usually a limitation of fine motor skills such as writing and the manipulation of toys. ${ }^{4}$ Children with CP may develop long-term structural and functional difficulties such as development of thumb-in-hand deformity, metacarpophalangeal joint dislocation, reduced limb growth, or upper limb muscle weakness. This hinders opposition and grasp movements which result in reduced bilateral dexterity function, a neglecting of the involved limb and possibly a reliance on others to complete functional activities. ${ }^{5}$ 
The typical management of a child with $\mathrm{CP}$ will include a conventional physiotherapy program consisting of stretching, strengthening, positioning, splinting, casting, and the facilitation of movement.6,7 The recent advances in computer technology have enabled clinicians to explore the use of virtual reality (VR) as an alternative treatment modality to treat children with $C \mathrm{P}^{8-11} \mathrm{VR}$ is reported to augment the desirable motor performance because of brain plasticity and brain reorganization through active participation, receiving feedback, and repetition of movements. ${ }^{12}$ VR increases the exercise compliance level in achieving selective motor control and enhances conventional physiotherapy effectiveness. ${ }^{13}$ Luna-Oliva et $\mathrm{al}^{10}$ showed improvement in the motor and processing skills, balance, gait speed, running, jumping, and manual dexterity in children with $\mathrm{CP}$ after 8 weeks of VR intervention. However, an explorative study that examined the upper limb functions using the commercially available VR intervention for a 6-week period reported no improvement of the quality of movement. ${ }^{14}$

VR combined with physiotherapy appears to be a promising new treatment approach with wider future applications. Research over the past decade using VR intervention has reported benefits to children with $C P .{ }^{12,15}$ VR may assist children in acquiring new motor skills, sustaining the benefits from exercise, and enabling children to use their hands for more functional skills. If this is indeed, the case the combined approach may have the potential to greatly enhance the abilities of the child, improving independence alongside minimizing secondary implications associated with growth and development. The upper extremity consists of shoulder complex, elbow, and hand components. The neural innervation and cortical representation for hands is higher than the shoulders and elbows. Although the shoulder provides stability, hand components are designed to do the fine motor activities. Children with CP can move the shoulder joints through atypical movement pattern but often struggle to move their hands in a coordinated way to produce the desired fine motor skills. ${ }^{16}$ Previous systematic reviews (SRs) examined the effect of VR in upper limbs and the general therapeutic effects in children with $C P{ }^{15,17-19}$ Currently, there is no SR that evaluates the effectiveness of VR in the treatment of hand function in children with CP. This review will bridge the gap and may assist in guiding future research projects and the therapeutic use of VR. This review therefore seeks to evaluate the effect of VR intervention when used in treatment aimed at improving hand function in children with $\mathrm{CP}$.

The International Classification of Functioning, Disability and Health (ICF) framework has been widely used in rehabilitation research to report the theoretical framework and the outcome evaluation of the intervention. ${ }^{20}$ The ICF domain consists of function (body structures and function), activity, and participation (capacity and performance) level. ICF-related hand functions can be described as "performing the coordinated actions of handling objects, picking up, manipulating, and releasing them using one's hand, fingers, and thumb." 21 Problems with regulating selective motor control, tone, and the associated growth-related neuromusculoskeletal changes limit the use of hands for functional skills especially for the children with hemiplegic distribution. Sixty percent of children with hemiplegic CP (4-16 years) were reported to have difficulties in performing arm-hand function-related activities of daily living. ${ }^{22,23}$ This may restrict social participation and decrease their quality of life. ${ }^{24}$ Our objective was to determine how effective the use of VR intervention is in improving the hand function in children with CP. It was compared with conventional physiotherapy treatment or other therapeutic interventions. The outcome of this review was categorized according to the ICF dimensions.

\section{Materials and methods}

The review protocol was published in International prospective register of systematic reviews (PROSPERO) website (registration no: CRD42015015931). ${ }^{25}$ The preferred reporting items for SRs and meta-analysis statement framework were followed for reporting. ${ }^{26}$

\section{Search strategy}

A comprehensive search was carried out in December 2014 in MEDLINE via Ovid (1950-current), CINAHL via EBSCO, ERIC via EBSCO, HealthSTAR (1982-current), AMED via Ovid (1985 to present), British Nursing Index via Proquest (1992-present), EMBASE via Ovid (1980-present), PsycINFO via EBSCO (1806-current), PEDro, Cochrane Central Register, DARE, OTSeeker, REHABDATA, HaPI, CIRRIE, and Scopus. The unpublished and ongoing clinical trial information from the following major trial register web sites were searched www.clinicaltrials.gov, apps.who.int/trialsearch/, and www.isrctn.com/. An additional search was carried out after 8 months of the original search (January 2015-August 2015) in line with the protocol.

Corresponding authors of the selected articles were contacted to provide the details of any other VR-related research studies in CP either by their team or by their associates and research group. Citation searching, scanning the conference proceedings, and dissertation abstracts were performed. The VR equipment manufacturers (Nintendo, Sony, GestureTek, NeuroVR, Hocoma, Motek, Virtual Realities, Haptic Master, Microsoft Xbox, Essential Reality, SensAble, Novint, and Cyberglove) were contacted and asked to provide any relevant research carried out using their product with children affected by $\mathrm{CP}$.

\section{Search terms and types of studies}

The relevant search terms from the Cochrane reviews and protocols related to VR interventions and $\mathrm{CP}$ were used. ${ }^{6,27-31} \mathrm{~A}$ comprehensive list of those terms with the Boolean operation plan is provided in Appendix 1. A broad search strategy including freetext words, medical subject heading, and all thesaurus subject terms were used in the database wherever applicable. Only the randomized controlled trials (RCTs) were included for this review, and all the other types of studies were excluded.

\section{Inclusion and exclusion criteria}

Searches were confined to children with CP only (age group 0-18 years). All the subgroups of $\mathrm{CP}$ were included, and children with acquired neurological disorder and the adult population were excluded. Some studies include adolescent population (15-25 years), and they were considered for this review if more than $50 \%$ of the participants were younger than 18 years old. Studies that examined the effect of VR intervention as one of the intervention methods on hand function as either a primary or secondary objective were included. No exclusion criteria were set for either language or publication years.

\section{Study selection}

A review team that consists of 4 reviewers selected the studies. The collected titles and structured abstracts from the electronic database were scrutinized independently by 2 reviewers (C.R. and V.M.). The other 2 reviewers (J.P. and K.S.N.) searched the potential studies from the conference proceedings, dissertation abstracts, and trial registers. The set inclusion and exclusion criteria were 
used to guide the selection of articles. Any difference of opinion was resolved through discussion and a consensus meeting. Full articles that met the selection criteria from the aforementioned source were collected, and the reviewers collectively decided which articles were suitable for the final review.

\section{Data extraction}

The methodological qualities of the included RCTs were examined by 2 reviewers (C.R. and V.M.) using the Cochrane collaboration's risk of bias tool. The reviewers extracted the data from the included RCTs and classified them under the ICF domains.

\section{Results}

The comprehensive electronic search identified 2204 studies from the database search, and 13 studies were included after scanning the titles and abstracts. Reviewers then retrieved all the 13 full-text articles, of these $6 \mathrm{RCTs}^{8,32-36}$ were included in the final review (5 full-text articles and 1 conference abstract). The reviewers could not find any relevant studies from the dissertation database. Most of the equipment manufacturers responded to our query, but all of them confirmed that they do not have the details of any studies relevant to this review. A summary of the selection process is given in Figure 1. The demographic data, VR equipment, and outcome measures used in the included RCTs is given in Table 1. Studies were included if they were not specifically examining hand function but where it was possible to extract information about hand function-related findings, and a summary of the included studies is given in Table 2. The ICF related details reported in the included studies were given in Table 3. Quantitative data synthesis through meta-analysis was not considered because of the heterogeneity of the outcome measures used in the included studies.

\section{Quality}

The methodological qualities of the included RCTs are given in Figure 2. A brief description of the included RCTs and the related ICF domains is given in the following section.

Reid and Campbell ${ }^{32}$ investigated the quality of upper limb movements using VR and standard care and found no difference in upper limb functions between the control and intervention group. The authors did not offer any reasons for this result but felt that the 8 weeks duration may not have been sufficient to produce an effect. In addition, a high number of dropouts in the control group and variability of the participants were reported in this study. The authors used the disassociation subsection of the Quality of upperextremity skills test to measure motor performance (ICF activity domain) and the Canadian occupational performance measure to measure the participants' performance and satisfaction (ICF
Potentially relevant citations after electronic search $(n=2204)$

First screening of titles and abstracts

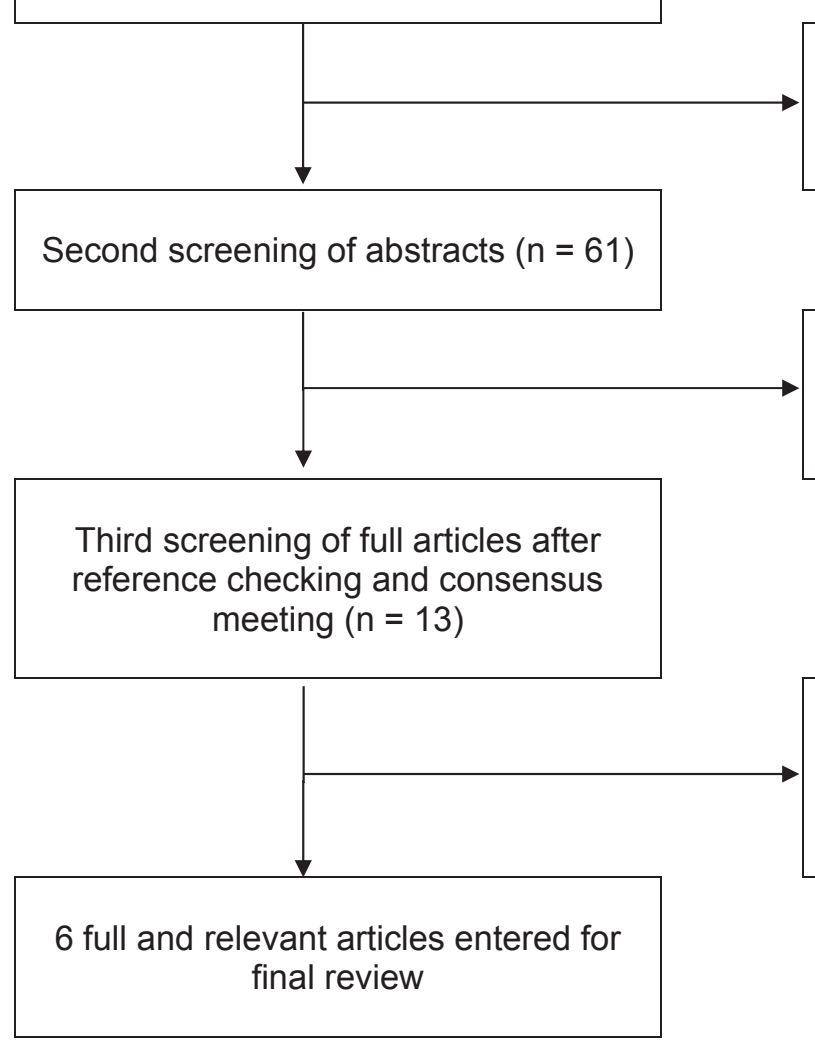

Reasons for exclusion

2143 titles excluded as clearly not relevant

39 - Not relevant and non RCTs 9 - Other therapy
4 - Systematic reviews

3 - Robotic therapy

Fig. 1. Flow of studies in systematic review. RCT $=$ randomized controlled trial. 
Table 1

Summary of the included studies and the intervention detail

\begin{tabular}{|c|c|c|c|c|c|c|c|c|c|c|c|c|}
\hline \multirow[t]{2}{*}{ Authors } & \multirow[t]{2}{*}{ Objective of the study } & \multirow{2}{*}{$\begin{array}{l}\text { Cerebral } \\
\text { palsy type }\end{array}$} & \multirow[t]{2}{*}{ GMFCS } & \multirow{2}{*}{$\begin{array}{l}\text { Age and number } \\
\text { of participants }\end{array}$} & \multicolumn{2}{|l|}{ VR intervention } & \multicolumn{2}{|l|}{ Control } & \multicolumn{4}{|c|}{ Other intervention } \\
\hline & & & & & $\begin{array}{l}\text { Type of VR } \\
\text { (name of the system) }\end{array}$ & Duration & Type & Duration & Type & Duration & Type & Duration \\
\hline $\begin{array}{l}\text { Reid and } \\
\text { Campbell } \\
(2006)^{32}\end{array}$ & $\begin{array}{l}\text { To see if changes in } \\
\text { the quality of upper } \\
\text { extremity movement } \\
\text { and in self-perceived } \\
\text { self-efficacy and self- } \\
\text { concept could be } \\
\text { found as a result of VR } \\
\text { intervention }\end{array}$ & $\begin{array}{l}\text { Not } \\
\text { specified }\end{array}$ & $\begin{array}{l}\text { Yes (level } \\
\text { I, III, IV, } \\
\text { and V) }\end{array}$ & $\begin{array}{l}8-13 \text { y } \\
n=40 \\
\text { (intervention = 20; } \\
\text { control =20) }\end{array}$ & $\begin{array}{l}\text { Nonimmersion } \\
\text { (name of the } \\
\text { system was } \\
\text { not specified) }\end{array}$ & $\begin{array}{l}90 \mathrm{~min} / \\
\text { session/1 } \\
\text { session/wk/ } \\
8 \mathrm{wk}\end{array}$ & $\begin{array}{l}\text { Physiotherapy } \\
\text { and } \\
\text { occupational } \\
\text { therapy }\end{array}$ & $\begin{array}{l}\text { Once a week } \\
\text { (no specific } \\
\text { detail about the } \\
\text { individual } \\
\text { session } \\
\text { duration } \\
\text { available) }\end{array}$ & & & & \\
\hline $\begin{array}{l}\text { Jannink, M } \\
\text { et al } \\
(2008)^{33}\end{array}$ & $\begin{array}{l}\text { To determine the user } \\
\text { satisfaction of the } \\
\text { EyeToy for the } \\
\text { training of the upper } \\
\text { limb in children with } \\
\text { cerebral palsy (CP) }\end{array}$ & $\begin{array}{l}\text { Hemiplegia, } \\
\text { diplegia and } \\
\text { quadriplegia } \\
\text { (spastic) }\end{array}$ & No & $\begin{array}{l}7-16 \text { y } \\
n=10 \\
(\text { Intervention = 5; } \\
\text { control = 5) }\end{array}$ & $\begin{array}{l}\text { Non-immersion } \\
\text { (EyeToy: Play-Sony } \\
\text { computer } \\
\text { Entertainment) }\end{array}$ & $\begin{array}{l}30 \mathrm{~min} / \\
\text { session/2 } \\
\text { session/wk/ } \\
6 \mathrm{wk}\end{array}$ & $\begin{array}{l}\text { Regular therapy } \\
\text { (physiotherapy) }\end{array}$ & $\begin{array}{l}30 \mathrm{~min} / \mathrm{session} / \\
2 \mathrm{session} / \\
\text { wk/6 wk }\end{array}$ & & & & \\
\hline $\begin{array}{l}\text { Rostami, H } \\
\quad \text { et al } \\
(2012)^{34}\end{array}$ & $\begin{array}{l}\text { To determine effects } \\
\text { of implementing a } \\
\text { practice period of } \\
\text { modified constraint- } \\
\text { induced movement } \\
\text { therapy (CIMT) in a } \\
\text { virtual environment } \\
\text { on upper limb } \\
\text { function in children } \\
\text { with spastic } \\
\text { hemiparetic cerebral } \\
\text { palsy }\end{array}$ & $\begin{array}{l}\text { Hemiplegia } \\
\text { (spastic) }\end{array}$ & No & $\begin{array}{l}6.2-11.8 \text { y } \\
n=32 \text { ( } 8 \text { children } \\
\text { in each group) }\end{array}$ & $\begin{array}{l}\text { Nonimmersion } \\
\text { (E-link evaluation } \\
\text { and exercise system } \\
\text { [version 6]) + } \\
\text { conventional } \\
\text { treatment }\end{array}$ & $\begin{array}{l}90 \mathrm{~min} / \\
\text { session/ } \\
3 \text { session/wk/ } \\
4 \mathrm{wk}+ \\
\text { conventional } \\
\text { treatment }\end{array}$ & Physiotherapy & $\begin{array}{l}30 \mathrm{~min} / \mathrm{session} / \\
2 \mathrm{session} / \mathrm{wk} / \\
4 \mathrm{wk}\end{array}$ & $\begin{array}{l}\text { Modified } \\
\text { CIMT }\end{array}$ & $\begin{array}{l}90 \mathrm{~min} / \\
\text { session/ } \\
3 \mathrm{session} / \mathrm{wk} / \\
4 \mathrm{wk}+ \\
\text { conventional } \\
\text { treatment }\end{array}$ & $\begin{array}{l}\text { VR }+ \text { modified } \\
\text { CIMT }+ \\
\text { conventional } \\
\text { treatment }\end{array}$ & $\begin{array}{l}90 \mathrm{~min} / \\
\text { session/ } \\
3 \text { session/wk/ } \\
4 \mathrm{wk}+ \\
\text { conventional } \\
\text { treatment }\end{array}$ \\
\hline $\begin{array}{l}\text { Sharan, D } \\
\text { et al } \\
(2012)^{8}\end{array}$ & $\begin{array}{l}\text { To evaluate the effect } \\
\text { of VRBT on balance, } \\
\text { manual ability, level } \\
\text { of the participation, } \\
\text { and satisfaction } \\
\text { among the } \\
\text { postoperative } \\
\text { children, suffering } \\
\text { from cerebral palsy, } \\
\text { who were going } \\
\text { through a } \\
\text { rehabilitation process }\end{array}$ & $\begin{array}{l}\text { Not } \\
\text { specified }\end{array}$ & No & $\begin{array}{l}\text { Age range was not } \\
\text { given; } n=16 \\
\text { (intervention }=8 ; \\
\text { control }=8 \text { ) }\end{array}$ & $\begin{array}{l}\text { Nonimmersion } \\
\text { (Nintendo Wii } \\
\text { Fit) + conventional } \\
\text { rehabilitation } \\
\text { modalities }\end{array}$ & $\begin{array}{l}\text { No specific } \\
\text { information } \\
\text { related to } \\
\text { duration } \\
\text { available } 3 \mathrm{~d} / \\
\text { wk/3 wk }\end{array}$ & $\begin{array}{l}\text { Conventional } \\
\text { rehabilitation } \\
\text { modalities }\end{array}$ & $\begin{array}{l}\text { No specific detail } \\
\text { about the } \\
\text { individual } \\
\text { session } \\
\text { duration/wk } \\
\text { available }\end{array}$ & & & & \\
\hline $\begin{array}{l}\text { Ko, Y et al } \\
\qquad(2013)^{35}\end{array}$ & $\begin{array}{l}\text { To determine } \\
\text { whether a VR sports } \\
\text { game is effective in } \\
\text { improving sport- } \\
\text { specific skills and } \\
\text { compare its result } \\
\text { with the } \\
\text { conventional therapy }\end{array}$ & $\begin{array}{l}\text { Hemiplegia } \\
\text { (tone not } \\
\text { specified) }\end{array}$ & $\begin{array}{l}\text { Yes (level } \\
\text { I and II) }\end{array}$ & $\begin{array}{l}6-18 y \\
n=26\end{array}$ & $\begin{array}{l}\text { Nonimmersion } \\
\text { (Microsoft XBOX360 } \\
\text { Kinect sports) }\end{array}$ & $\begin{array}{l}90 \mathrm{~min} / \mathrm{wk} \\
\text { for } 6 \mathrm{wk} \text {, }\end{array}$ & $\begin{array}{l}\text { Strengthening } \\
\text { exercise }\end{array}$ & $\begin{array}{l}\text { No specific detail } \\
\text { about the } \\
\text { individual } \\
\text { session duration } \\
\text { available }\end{array}$ & & & & \\
\hline $\begin{array}{l}\text { Chiu, } \mathrm{H} \text { et al } \\
\quad(2014)^{36}\end{array}$ & $\begin{array}{l}\text { To investigate } \\
\text { whether Wii Sports } \\
\text { Resort training is } \\
\text { effective and if any } \\
\text { benefits are } \\
\text { maintained }\end{array}$ & $\begin{array}{l}\text { Hemiplegia } \\
\text { (spastic) }\end{array}$ & $\begin{array}{l}\text { Yes } \\
\text { (I to V) }\end{array}$ & $\begin{array}{l}6-13 \mathrm{y} \\
n=62 \\
\text { (Intervention = 32; } \\
\text { control = 30) }\end{array}$ & $\begin{array}{l}\text { Nonimmersion } \\
\text { (Wii Sports } \\
\text { Resort) + usual } \\
\text { therapy (upper limb } \\
\text { training) }\end{array}$ & $\begin{array}{l}40 \mathrm{~min} / \\
\text { session/ } \\
3 \mathrm{session} / \mathrm{wk} / \\
6 \mathrm{wk}+\text { usual } \\
\text { therapy } \\
\text { (upper limb } \\
\text { training) }\end{array}$ & $\begin{array}{l}\text { Usual therapy } \\
\text { (upper limb } \\
\text { training) }\end{array}$ & Not specified & & & & \\
\hline
\end{tabular}


Table 2

Summary of studies (drop out, outcome measures, and additional detail and comments)

\begin{tabular}{|c|c|c|c|c|c|c|c|}
\hline Authors & $\begin{array}{l}\text { Statistical } \\
\text { analysis }\end{array}$ & $\begin{array}{l}\text { Drop outs } \\
\text { stated }\end{array}$ & No of dropouts & Follow-up & Outcome measures used & $\begin{array}{l}\text { Changes in } \\
\text { hand function }\end{array}$ & $\begin{array}{l}\text { Additional detail and } \\
\text { comments }\end{array}$ \\
\hline $\begin{array}{l}\text { Reid and } \\
\text { Campbell } \\
(2006)^{32}\end{array}$ & $t$ test & Yes & $\begin{array}{l}\text { Intervention }(n=1) \\
\text { Control }(n=8)\end{array}$ & No & $\begin{array}{l}\text { Canadian occupational } \\
\text { performance measure (COPM) } \\
\text { Self-perception profile for } \\
\text { children (SPCC) } \\
\text { Quality of upper extremity } \\
\text { skills test (QUEST) }\end{array}$ & No & $\begin{array}{l}\text { VR is not more effective than } \\
\text { regular PT or OT intervention. } \\
\text { High number of lost to follow- } \\
\text { up in the control group. }\end{array}$ \\
\hline $\begin{array}{l}\text { Jannink, M et al } \\
\qquad(2008)^{33}\end{array}$ & $\begin{array}{l}\text { Percentage } \\
\text { score }\end{array}$ & No & 0 & No & $\begin{array}{l}\text { Melbourne Assessment of } \\
\text { Unilateral Upper Limb test }\end{array}$ & Yes & $\begin{array}{l}\text { Very minimal change in hand } \\
\text { function; very small sample } \\
\text { size, therefore result can not be } \\
\text { reliably supporting the use of } \\
\text { VR to improve hand-function }\end{array}$ \\
\hline $\begin{array}{l}\text { Rostami, H et al } \\
\qquad(2012)^{34}\end{array}$ & $\begin{array}{l}\text { ANOVA with } \\
\text { repeated } \\
\text { measures }\end{array}$ & Yes & 0 & $\begin{array}{l}\text { Yes ( } 3 \text { mo of } \\
\text { follow-up) }\end{array}$ & $\begin{array}{l}\text { Paediatric motor activity log } \\
\text { (PMAL) } \\
\text { Bruininks-Oseretsky test for } \\
\text { motor proficiency (speed and } \\
\text { dexterity subtest) }\end{array}$ & Yes & $\begin{array}{l}\text { VR combined with regular } \\
\text { physiotherapy is more } \\
\text { beneficial than VR alone. } \\
\text { Improvement was maintained } \\
3 \text { mo after the intervention. }\end{array}$ \\
\hline $\begin{array}{l}\text { Sharan, D et al } \\
\qquad(2012)^{8}\end{array}$ & $t$ test & Not stated & Not stated & No & $\begin{array}{l}\text { Manual Ability } \\
\text { Classification System (MACS) } \\
\text { for upper limb function }\end{array}$ & Yes & $\begin{array}{l}\text { VR intervention is more } \\
\text { effective. } \\
\text { Quality of study is very poor } \\
\text { (methodological flaw) }\end{array}$ \\
\hline $\begin{array}{l}\text { Ko, Y et al } \\
\qquad(2013)^{35}\end{array}$ & Not stated & Not stated & Not stated & No & $\begin{array}{l}\text { Melbourne assessment subscale } \\
\text { (unilateral upper limb function } \\
\text { [MULL]) }\end{array}$ & Yes & $\begin{array}{l}\text { VR intervention and } \\
\text { strengthening exercises has } \\
\text { similar effect. } \\
\text { No specific data available to } \\
\text { interpret the result in detail } \\
\text { from the conference abstract }\end{array}$ \\
\hline $\begin{array}{l}\text { Chiu, H et al } \\
\qquad(2014)^{36}\end{array}$ & $\begin{array}{l}\text { Two-way } \\
\text { ANOVA; ITT }\end{array}$ & Yes & $\begin{array}{l}\text { Intervention }(n=2) \\
\text { Control }(n=3)\end{array}$ & $\begin{array}{l}\text { Yes ( } 3 \text { mo } \\
\text { follow-up) }\end{array}$ & $\begin{array}{l}\text { Nine-hole peg test } \\
\text { Jebsen-Taylor test of hand } \\
\text { function }\end{array}$ & No & $\begin{array}{l}\text { Wii Sports Resort did not } \\
\text { improve hand function }\end{array}$ \\
\hline
\end{tabular}

ANOVA = analysis of variance; VR = virtual reality; VRBT $=$ virtual reality based therapy; PT $=$ physiotherapy; OT $=$ occupational therapy; ITT $=$ intention-to-treat.

participation domain). The authors noted improved activity level but no changes in participation level. This study did not examine the changes in the body structure and function sections of the ICF.

Jannink et $\mathrm{al}^{33}$ used VR for training of the upper limbs in children with CP $(n=10)$. They noticed some improvement, measured by the Melbourne assessment score in 2 participants in the intervention group (Gross motor functional classification system [GMFCS] level I), minimal regression in 2 children in the control

Table 3

International Classification of Functioning, Disability and Health related detail reported in the included studies

\begin{tabular}{|c|c|c|c|}
\hline \multirow[t]{2}{*}{ Study } & \multicolumn{3}{|c|}{$\begin{array}{l}\text { International Classification of Functioning, Disability and } \\
\text { Health (ICF) }\end{array}$} \\
\hline & $\begin{array}{l}\text { Body structure } \\
\text { and function } \\
\text { (result) }\end{array}$ & Activity (result) & $\begin{array}{l}\text { Participation } \\
\text { (result) }\end{array}$ \\
\hline $\begin{array}{l}\text { Reid and Campbell } \\
\qquad(2006)^{18,32}\end{array}$ & & QUEST $(\uparrow)$ & COPM (=) \\
\hline $\begin{array}{l}\text { Jannink, } M \text { et al } \\
(2008)^{18,33}\end{array}$ & & $\begin{array}{l}\text { Melbourne } \\
\text { assessment } \\
\text { subscale }(\uparrow)\end{array}$ & \\
\hline $\begin{array}{l}\text { Rostami, H et al } \\
\qquad(2012)^{18,34}\end{array}$ & & $\begin{array}{l}\text { BOTMP subset } 8:(\uparrow) \\
\text { Pediatric motor } \\
\text { activity } \log (\uparrow)\end{array}$ & \\
\hline $\begin{array}{l}\text { Sharan, D et al } \\
\qquad(2012)^{8}\end{array}$ & & $\begin{array}{l}\text { Manual ability } \\
\text { classification } \\
\text { system }(\uparrow)\end{array}$ & \\
\hline $\begin{array}{l}\text { Ko, Y. et al } \\
\quad(2013)^{35}\end{array}$ & Kinematics $(\uparrow)$ & $\begin{array}{l}\text { Melbourne } \\
\text { assessment } \\
\text { subscale (=) }\end{array}$ & \\
\hline $\begin{array}{l}\text { Chiu, } H \text { et al } \\
\quad(2014)^{36}\end{array}$ & $\begin{array}{l}\text { Grip strength and } \\
\text { coordination }(=)\end{array}$ & $\begin{array}{l}\text { Nine-hole peg test } \\
\text { and Jebsen total }(=)\end{array}$ & $\begin{array}{l}\text { Carers' } \\
\text { perception (=) }\end{array}$ \\
\hline
\end{tabular}

$==$ same in both groups; $\uparrow=$ increased; BOTMP = Bruininks-Oseretsky test for motor proficiency; QUEST = Quality of Upper Extremity Skills Test; COPM = Canadian Occupational Performance Measure. group (GMFCS level I and IV), and no changes in 1 participant (GMFCS IV) in both groups. Although the authors reported improved hand functions, their data do not reliably support the use of VR in children with CP. The authors considered cortical changes based on motor relearning through high repetition, augmented feedback, and motivation factors. The Melbourne assessment of unilateral upper limb function examines reach, grasp, release, and manipulation domains, but the authors gave no specific data indicating the changes in the body function and skills. The reviewers interpreted that the improved results were attributable to the activity level of ICF domain. Although the children were reportedly motivated and satisfied with the VR intervention, no specific tools were used to study their participation level.

Rostami et $\mathrm{al}^{34}$ examined the effect of constraint-induced movement therapy in a VR environment and found improvements in movement quality, speed and dexterity with a sustained effect shown 3 months after the intervention. They used VR as a tool for implementing constrained induced therapy. The authors attributed repetitive practice, activation of new cortical circuits, and increased compliance as being the causes for the positive changes in hand function. The authors used the BruinninksOseretsky test for motor performance which examined the activity domain of the ICF, but no other tests were used to test the remaining ICF domains. However, the increased speed and dexterity of Bruinninks-Oseretsky test for motor performance and the fewer dropouts indicate active participation of the children in this study.

Sharan et $\mathrm{al}^{8}$ study was aimed at examining the effect of VR on balance and manual ability among the children with $\mathrm{CP}$ after surgery. The authors claimed improved hand function measured by the manual ability classification system and repetitive practice as an attributing factor for the improvement. The context of the improved hand function related to the activity domain of the ICF was not explained adequately, and no specific information was 


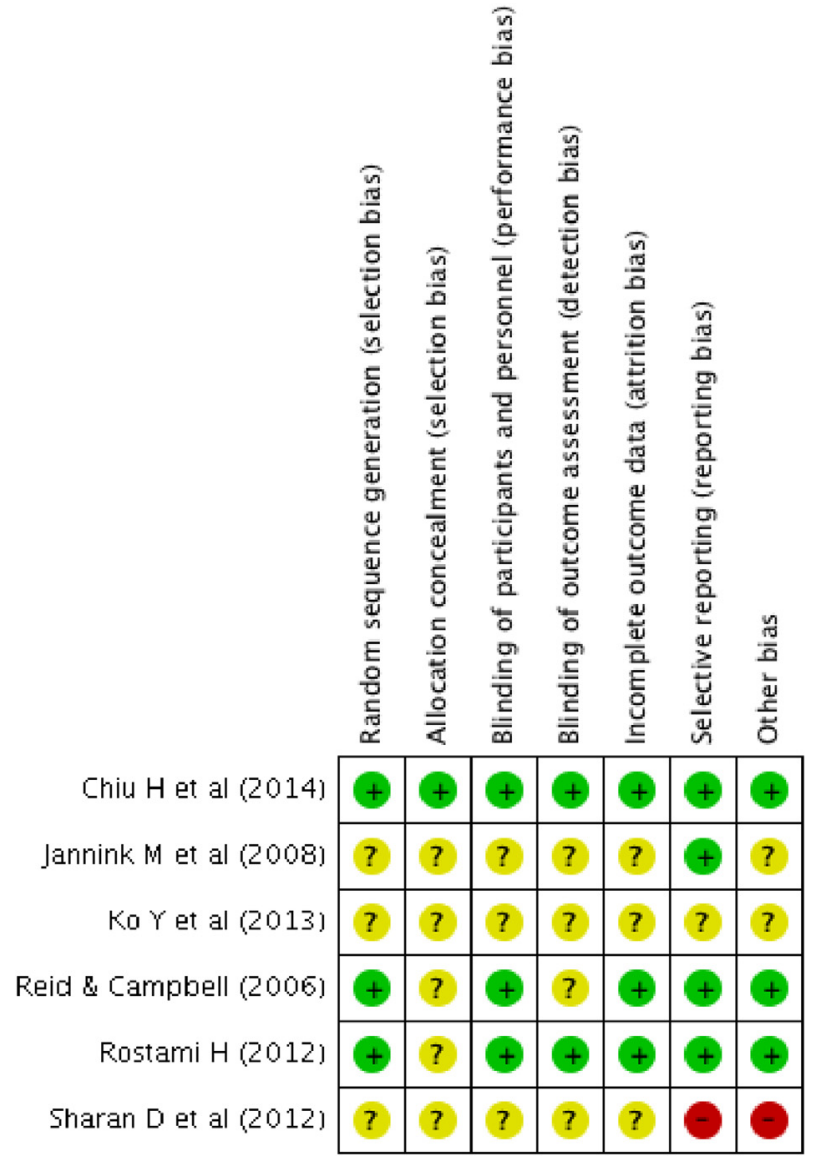

Fig. 2. Review authors' judgment of methodological quality summary of the included studies.

available to indicate the structure and functional change of the ICF domain. The participation domain of the ICF was addressed by the authors through higher participation level, satisfaction, cooperation, and motivation, but it was unclear how this was measured.

Ko et $\mathrm{al}^{35}$ studied the effect of VR intervention for children with hemiplegic $\mathrm{CP}$ and reported improved hand function. This could be due to the fact that their sample consists of the children who are capable of performing at near-normal level (GMFCS level I and II). The authors offered no specific explanation for the improvement. This study looked at the body structure and function; and activity domains of the ICF, assessed by speed and dexterity; and the Melbourne assessment subscale, respectively. No specific information addressing the participation domain of ICF was available.

Chiu et $\mathrm{al}^{36}$ study had a high number of participants in their control and intervention group. The authors noted no statistical difference between the control and the intervention group in many items examined but noticed an improved trend in handgrip strength in the intervention group. Children with CP used their hemiplegic hand more to produce a power grip after practicing repeatedly; therefore, their hand muscle strength had improved. They reported sustained improvement in hand function even 6 weeks after the intervention and proposed that this could be due to permanent changes in the level of the children's everyday physical activity following the intervention. This study addressed the body structure and function (grip strength and coordination), activity (nine-hole peg test and Jebsen total test) and participation (carers' perception) domains of the ICF. However, the authors found no difference between the intervention and control group.
International Classification of Functioning, Disability and Health

Chiu et $\mathrm{al}^{36}$ reported no changes in hand grip strength and coordination between the intervention and control groups, but Ko et $\mathrm{al}^{35}$ reported increased mean peak velocity and other kinematic values. No specific data are available from conference abstract by Ko et al's, ${ }^{35}$ and the reviewers were unable to contact the authors to find out any further information. No changes between the intervention and control groups in the activity component of ICF was observed in 2 studies, ${ }^{35,36}$ but the remaining 4 studies did identify an improved activity level. ${ }^{8,18,32,33,35}$ Only 2 studies reported on the level of participation, and these studies noticed no significant difference between the study groups. ${ }^{18,32,36}$ Although findings of Chiu et $\mathrm{al}^{36}$ reflect the changes in all the ICF domains, the authors found no difference between the intervention and the control group. At 12 weeks, the authors' data show that the carers' perception of quantity had a statistical significance between the groups; however, there was no statistical difference noticed in the quality.

\section{Adverse effects}

Jannink et $\mathrm{al}^{33}$ explicitly reported that they found no adverse effects with the use of VR. Conversely, their data suggest a very minimal reduction of hand function in 2 participants, but the authors gave no specific explanation for this. No other studies have reported any adverse effects or deterioration in either their control or intervention group. However, an absence of reported adverse events does not necessarily mean that none exist. Most of the studies have a small sample size, which may not have been sufficiently powered to detect adverse effects.

\section{Discussion}

Our SR found that the evidence supporting the use of VR in improving hand function compared to conventional physiotherapy in children with CP is exploratory and weak in nature. Four studies reported improved hand function. ${ }^{8,33-35}$ Rostami et al $^{34}$ findings are in favor of VR, and the authors' findings and the mechanics for hand function improvements are in agreement with those of Luna-Oliva et al. ${ }^{10}$ Although Jannink et $\mathrm{al}^{33}$ reported minimal changes in hand function, their results cannot reliably support the use of VR due to their very small sample size. Sharan et $\mathrm{al}^{8}$ reported improvement in hand function, but it was not clear if the children had undergone any upper limb surgery and whether the VR was used for rehabilitation. The outcome measure used by Sharan et $\mathrm{al}^{8}$ was not designed to measure hand function but to classify the upper limb function level; therefore, their conclusion has to be interpreted cautiously.

All the included RCTs used nonimmersion VR techniques in the experimental group. It was noticed that the study findings from Rostami et al $^{34}$ suggested that 4 weeks of intervention ( 3 sessions/ wk) resulted in improved hand function. Chiu et al $^{36}$ suggested that at least 6 weeks of intervention is required to find a measurable effect on hand function. However, Reid and Campbell ${ }^{32}$ commented that 8 weeks of intervention ( 1 session/wk) may not be sufficient to produce any meaningful changes. Rostami et al $^{34}$ total duration of intensive intervention for VR group was 1080 minutes in 4 weeks when compared with Reid and Campbell which was 720 minutes in 8 weeks. This suggests that an intensive VR intervention may be more likely to result in improvement.

\section{International Classification of Functioning, Disability and Health}

All the RCTs reported the activity element of ICF but no study explicitly described the effect of VR intervention based on the ICF 
model. Changes in the structural and functional components were reported by Chiu et $\mathrm{al}^{36}$ and Ko et $\mathrm{al}^{35}$ but their studies used different outcome measures. It was difficult to establish any relationship between the ICF domains between the included RCTs.

\section{Clinical implication}

This review extensively looked at the available literature in all the major databases, and only the RCTs were included. Four studies reported some improvement in hand function and it is interesting to note that of these, 3 have children with hemiplegic $C P$ as subjects; a possible deduction is that VR is a useful tool to improve hand function in children with hemiplegic CP. However, apart from the outcome reported by Rostami et $\mathrm{al}^{34}$ which has a low risk bias; the other studies cannot be used to reliably support this view due to a high risk of bias. We were unable to perform a meta-analysis to examine the effect size due to the heterogeneity of the outcome measures used. We suggest that further studies on this CP subgroup with a larger sample size would be required to investigate this further.

The existing reviews reported the improved motivational factor and high parental satisfaction, but our study did not examine this component. Our review is in agreement with the other reviews that the available evidence from the existing studies was inconsistent and that VR cannot be reliably suggested to improve hand function until further studies have ascertained its therapeutic effect. ${ }^{15,17,18,37}$ The limited availability of the RCTs in this area, small sample size, nonuniformity of the outcome measures used, and variable study duration and the techniques used should be taken into account when drawing the aforementioned conclusion. Studies have shown improved hand and arm functions with intensive VR intervention for children with $\mathrm{CP}^{9,38}$ It was acknowledged that blinding and randomization in a CP cohort is difficult; therefore, well-designed non-RCTs that address the ICF domains could support VR to improve hand function in children with $\mathrm{CP}$.

Some of the responses received from the VR manufacturers highlighted that their products were not designed for people with a disability. The children's hand function may have been improved if the equipment was specifically designed to accommodate this factor. This could be an area for future investigation.

\section{Weakness}

This study excluded the non-RCTs; before and after studies; interrupted time series; and cohort studies, thus preventing the reporting of some important findings. It also did not examine the cost-benefit analysis of VR intervention. In the protocol, the review team intended to select the studies that used those outcome measures suggested by Hoare et al. ${ }^{28,31}$ Unfortunately the heterogeneity of $\mathrm{CP}$ and the variations in the outcome measures, which were used in the selected studies, led us to accept all of the outcome measures irrespective of their reliability and validity. This was one of the main deviations from the protocol and consequently introduced some bias. The review team was unable to access all the conference proceedings as described in the protocol, and therefore, some potentially important studies may have been missed.

\section{Conclusion}

This review was aimed at assessing the improvement in hand function of children with CP using VR. The strength of the evidence supporting the use of VR to improve changes in hand function is weak; therefore, VR may be used as an adjunct to therapy. Further high-quality RCTs with a larger sample size that address the ICF dimensions are required to investigate the actual benefits of VR in children with CP.

\section{Acknowledgment}

The authors thank Mrs. Claire Sharp, Occupational therapist, for constructive comments.

\section{Supplementary data}

Supplementary data related to this article can be found at https://doi.org/10.1016/j.jht.2018.01.006.

\section{References}

1. Rosenbaum P, Paneth N, Leviton A, et al. A report: the definition and classification of cerebral palsy April 2006. Dev Med Child Neurol. 2007;49(suppl 109): $8-14$

2. Opheim A, Jahnsen R, Olsson E, Stanghelle JK. Walking function, pain, and fatigue in adults with cerebral palsy: a 7-year follow-up study. Dev Med Child Neurol. 2009:51(5):381-388.

3. Thorley M, Donaghey S, Edwards P, et al. Evaluation of the effects of botulinum toxin A injections when used to improve ease of care and comfort in children with cerebral palsy whom are non-ambulant: a double blind randomized controlled trial. BMC Pediatr. 2012;12:120.

4. Boyd RN, Morris ME, Graham HK. Management of upper limb dysfunction in children with cerebral palsy: a systematic review. Eur J Neurol. 2001;8(supp 5):150-166.

5. Basu AP, Pearse J, Kelly S, Wisher V, Kisler J. Early intervention to improve hand function in hemiplegic cerebral palsy. Front Neurol. 2014;5:281.

6. Hoare BJ, Wallen MA, Imms C, Villanueva E, Rawicki HB, Carey L. Botulinum toxin $\mathrm{A}$ as an adjunct to treatment in the management of the upper limb in children with spastic cerebral palsy (UPDATE). Cochrane Database Syst Rev. 2010;(1):CD003469.

7. Martin L, Baker R, Harvey A. A systematic review of common physiotherapy interventions in school-aged children with cerebral palsy. Phys Occup Ther Pediatr. 2010;30(4):294-312.

8. Sharan D, Ajeesh PS, Rameshkumar R, Mathankumar M, Paulina RJ, Manjula M. Virtual reality based therapy for post operative rehabilitation of children with cerebral palsy. Work. 2012;41(Suppl 1):3612-3615.

9. Golomb MR, Warden SJ, Fess E, et al. Maintained hand function and forearm bone health 14 months after an in-home virtual-reality videogame hand telerehabilitation intervention in an adolescent with hemiplegic cerebral palsy. I Child Neurol. 2011;26(3):389-393.

10. Luna-Oliva L, Ortiz-Gutierrez RM, Cano-de la Cuerda R, et al. Kinect Xbox 360 as a therapeutic modality for children with cerebral palsy in a school environment: a preliminary study. NeuroRehabilitation. 2013;33(4):513-521.

11. Riener R, Dislaki E, Keller U, Koenig A, Van Hedel H, Nagle A. Virtual reality aided training of combined arm and leg movements of children with CP. Stud Health Technol Inform. 2013;184:349-355.

12. Snider L, Majnemer A, Darsaklis V. Virtual reality as a therapeutic modality for children with cerebral palsy. Dev Neurorehabil. 2010;13(2):120-128.

13. Bryanton C, Bosse J, Brien M, McLean J, McCormick A, Sveistrup H. Feasibility motivation, and selective motor control: virtual reality compared to conventional home exercise in children with cerebral palsy. Cyberpsychol Behav. 2006;9(2):123-128.

14. Winkels DGM, Kottink AIR, Temmink RAJ, Nijlant JMM, Buurke JH. Wii-habilitation of upper extremity function in children with cerebral palsy. An explorative study. Dev Neurorehabil. 2013;16(1):44-51.

15. Galvin J, McDonald R, Catroppa C, Anderson V. Does intervention using virtua reality improve upper limb function in children with neurological impairment: a systematic review of the evidence. Brain Inj. 2011;25(5):435-442.

16. Vaz DV, Mancini MC, Fonseca ST, Vieira DSR, Pertence AEM. Muscle stiffness and strength and their relation to hand function in children with hemiplegic cerebral palsy. Dev Med Child Neurol. 2006;48:728-733.

17. Chiu H-C, Kuo P. Effect of virtual reality in children with cerebral palsy: a systematic review. In: Source: 27th Annual Meeting of the European Academy of Childhood Disability (EACD), 27-30 May 2015, Copenhagen, Denmark. 2015.

18. Chen Y, Lee S-Y, Howard AM. Effect of virtual reality on upper extremity function in children with cerebral palsy: a meta-analysis. Pediatr Phys Ther 2014:26(3):289-300.

19. Laufer Y, Weiss PTL. Virtual reality in the assessment and treatment of children with motor impairment: a systematic review. J Phys Ther Educ. 2011;25(1):59.

20. Maribo $T$, Petersen $\mathrm{KS}$, Handberg $C$, et al. Systematic literature review on IC from 2001 to 2013 in the Nordic Countries Focusing on clinical and rehabilitation context. J Clin Med Res. 2016;8(1):1-9. 
21. Fine hand use (d440). Available at: http://apps.who.int/classifications/icfbrowser/hand. Accessed November 2, 2017.

22. van Eck M, Dallmeijer AJ, van Lith IS, Voorman JM, Becher J. Manual ability and its relationship with daily activities in adolescents with cerebral palsy.J Rehabil Med. 2010;42(5):493-498.

23. Arner M, Eliasson A-C, Nicklasson S, Sommerstein K, Hagglund G. Hand function in cerebral palsy. Report of 367 children in a population-based longitudinal health care program. J Hand Surg Am. 2008;33(8):13371347.

24. Lemmens RJ, Janssen-Potten YJ, Timmermans AA, Defesche A, Smeets RJ, Seelen HA. Arm hand skilled performance in cerebral palsy: activity preferences and their movement components. BMC Neurol. 2014;14:52.

25. Rathinam C, Mohan V, Peirson J, Skinner J, Subash-Netaji K, Kuhn I. Virtual Reality Children Cerebral Palsy A Systematic Review (protocol), PROSPERO. 2015. Available at: http://www.crd.york.ac.uk/PROSPERO/display_record.php? ID=CRD42015015931.

26. Liberati A, Altman DG, Tetzlaff J, et al. The PRISMA statement for reporting systematic reviews and meta-analyses of studies that evaluate healthcare interventions: explanation and elaboration. BMJ. 2009;339.

27. Hoare BJ, Wasiak J, Imms C, Carey L. Constraint-induced movement therapy in the treatment of the upper limb in children with hemiplegic cerebral palsy. Cochrane Database Syst Rev. 2007;(2):CD004149.

28. Ade-Hall RA, Moore AP. Botulinum toxin type A in the treatment of lower limb spasticity in cerebral palsy. Cochrane Database Syst Rev. 2000;(2): CD001408.

29. Battibugli S, Blumetti FC, Pinto JA, Tamaoki MJS, de Lourenço AF, Belloti JC. Electrical stimulation therapy for children with cerebral palsy. Cochrane Database Syst Rev. 2011;(12).
30. Dockx K, Bekkers EMJ, Van den Bergh V, et al. Virtual reality for rehabilitation in Parkinson's disease, Cochrane Database Syst Rev 12, 2016, CD010760. https:// doi.org/10.1002/14651858.CD010760.pub2.

31. Howard DC. Anti Spastic Medication for Spasticity in Cerebral Palsy, Movement Disorders Group: Cochrane Neurological Network, Cochrane Libr (4), 2001.

32. Reid D, Campbell K. The use of virtual reality with children with cerebral palsy: a pilot randomized trial. Ther Recreation J. 2006;40(4):255.

33. Jannink MJA, van der Wilden GJ, Navis DW, Visser G, Gussinklo J, Ijzerman M. A low-cost video game applied for training of upper extremity function in children with cerebral palsy: a pilot study. Cyberpsychol Behav. 2008;11(1): $27-32$.

34. Rostami HR, Arastoo AA, Nejad SJ, Mahany MK, Malamiri RA, Goharpey S. Effects of modified constraint-induced movement therapy in virtual environment on upper-limb function in children with spastic hemiparetic cerebral palsy: a randomised controlled trial. NeuroRehabilitation. 2012;31(4): 357-365.

35. Ko Y, Kim H, Chio E, Lee S. Do virtual reality sports games improve sports specific skills in unilateral cerebral palsy patients? Dev Med Child Neurol. 2013;55:12-13.

36. Chiu H-C, Ada L, Lee H-M. Upper limb training using Wii Sports Resort for children with hemiplegic cerebral palsy: a randomized, single-blind trial. Clin Rehabil. 2014;28(10):1015-1024.

37. Fehlings D, Switzer L, Findlay B, Knights S. Interactive computer play as "motor therapy" for individuals with cerebral palsy. In: Seminars in Pediatric Neurology. Vol 20. New York, NY: Elsevier; 2013:127-138.

38. Do J-H, Yoo E-Y, Jung M-Y, Park HY. The effects of virtual reality-based bilateral arm training on hemiplegic children's upper limb motor skills. NeuroRehabilitation. 2016;38(2):115-127. 


\section{Appendix 1: Search terms}

[Database: Ovid MEDLINE(R) In-Process \& Other Non-Indexed Citations and Ovid MEDLINE(R) $<1946$ to Present $>$ ]

Search Strategy: medline- CP and VR and Child and RCT

1 exp child/

2 exp infant/

3 exp adolescent/

4 exp minors/

5 exp pediatrics/

6 (child* or infant* or newborn* or neonat* or baby or babies or adolescen* $^{*}$ or pediatric* or paediatric* or youth* or teen*).tw.

7 or $1-6$

8 randomized controlled trial.pt.

9 controlled clinical trial.pt.

10 randomized.ab.

11 placebo.ab.

12 randomly.ab.

13 trial.ab.

14 groups.ab.

15 or/8-14

16 virtual reality exposure therapy/

17 (virtual or virtually or VR).tw.

18 exp user computer interface/

19 exp computer simulation/

20 computer simulat*.tw.

21 ((simulat* or augement* or mediat*) adj3 (world* or realit* or environment*)).tw. (5593)

22 exp video games/
23 (videogame* or ((video or computer or electronic or online or on-line or simulation or role playing) adj game)).tw.

24 wii.tw. (356)

25 ((head or helmet) adj mounted).tw.

26 (immersi* $^{*}$ or spatial presence or lifelike or life-like).tw.

27 interactive*.tw.

28 augment $^{*}$.tw.

29 computer*.tw.

30 "serious gaming".tw.

31 software.tw.

32 "user-computer interface*".tw.

33 exergam*.tw.

34 "reality system*".tw.

35 (Nintendo or Sony or "GestureTek" or NeuroVR or Hocoma or Motek or "Virtual Realities" or "Haptic Master" or Microsoft or Xbox or "Essential Reality" or SensAble or Novint or Cyberglove).ti,ab.

36 or/16-35

37 exp cerebral palsy/

38 exp central nervous system diseases/

39 "little* disease*".tw.

40 exp nervous system diseases/

41 "nervous system disease*".tw.

42 "nervous system disorder*".tw.

43 (cerebral adj3 pals*).tw.

44 ((spastic* or dipleg* or monopleg* or quadripleg* $^{*}$ ) and (hypoton* or dyston* or dyskinetic*)).tw.

45 or/37-44

467 and 15 and 36 and 45

47 Repeat 46 in other database

48 Remove duplicate by combine 46 and 47 